\title{
Polyphenolic content of Vranec wines produced by different vinification conditions
}

\author{
Violeta Ivanova ${ }^{\mathrm{a}, \mathrm{b}}$, Ágnes Dörnyei ${ }^{\mathrm{c}, \mathrm{d}}$, László Márk ${ }^{\mathrm{e}}$, Borimir Vojnoski ${ }^{\mathrm{b}}$, Trajće Stafilov ${ }^{\mathrm{a}}$, \\ Marina Stefova ${ }^{a}$, Ferenc Kilár ${ }^{\mathrm{c}, \mathrm{d}, *}$ \\ a Institute of Chemistry, Faculty of Natural Sciences and Mathematics, Sts. Cyril and Methodius University, Arhimedova 5, 1001 Skopje, Macedonia \\ ${ }^{\mathrm{b}}$ Department for Enology, Institute of Agriculture, Sts. Cyril and Methodius University, Aleksandar Makedonski bb, 1000 Skopje, Macedonia \\ ${ }^{\mathrm{c}}$ Department of Analytical and Environmental Chemistry, Faculty of Science, University of Pécs, Ifjúság útja 6, H-7624 Pécs, Hungary \\ ${ }^{\mathrm{d}}$ Institute of Bioanalysis, Faculty of Medicine, University of Pécs, Szigeti út 12, H-7624 Pécs, Hungary \\ ${ }^{\mathrm{e}}$ Department of Biochemistry and Medical Chemistry, Faculty of Medicine, University of Pécs, Szigeti út 12, H-7624 Pécs, Hungary
}

\section{A R T I C L E I N F O}

\section{Article history:}

Received 23 February 2010

Received in revised form 7 April 2010

Accepted 10 June 2010

\section{Keywords:}

Wine

Polyphenols

HPLC-DAD-MS

Spectrophotometry

Winemaking

Maceration time

Sulphur dioxide

Yeast

\begin{abstract}
A B S T R A C T
Macedonian Vranec wines were analysed by HPLC coupled with DAD and MS detections and by spectrophotometric methods. ESI-IT MS and MS-MS methods with alternating ionisation polarity were used for identification of the phenolic compounds. Both, nonflavonoids (stilbens, hydroxybenzoic and hydroxycinnamic acids and derivatives) and flavonoids (flavonols, flavan-3-ols and anthocyanins) were detected in the samples. Vranec wines were produced under different fermentation conditions: maceration time of 3, 6 and 10 days, two doses of $\mathrm{SO}_{2}\left(30\right.$ and $70 \mathrm{mg} \mathrm{l}^{-1}$ ) and two yeasts for fermentation, in order to examine their effects on the extraction of phenolic compounds from grapes into the wine.
\end{abstract}

(c) 2010 Elsevier Ltd. All rights reserved.

\section{Introduction}

Polyphenols, which play an important role in the organoleptic characteristics of wine, are divided into two groups: flavonoids (anthocyanins, flavan-3-ols, flavonols and dihydroflavonols) and nonflavonoids (hydroxybenzoic and hydroxycinnamic acids and derivatives, stilbenes and volatile phenols). In particular, flavan3-ols (monomeric flavan-3-ols and proanthocyanidins) confer the astringency and structure to the beverage (Sarni-Manchado, Cheynier, \& Moutounet, 1999) and anthocyanins, as red pigments, are responsible for the colour of the wines (Chinnici, Sonni, Natali, Galassi, \& Riponi, 2009; Guerrero et al., 2009; Wulf \& Nagel, 1978).

The grape phenolic composition and content are affected by several factors such as grape variety, ripening stage, climate, soil, place of growing and vine cultivation. In addition, wine-making technologies (maceration time, temperature, intensity of pressing, yeast, $\mathrm{SO}_{2}$-doses) together with enological practices and ageing

\footnotetext{
* Corresponding author at: Institute of Bioanalysis, Faculty of Medicine, University of Pécs, Szigeti út 12, H-7624 Pécs, Hungary. Tel.: +36 72 536273; fax: +36 72 536254.

E-mail address: ferenc.kilar@aok.pte.hu (F. Kilár).
}

also modify it. There are published data for the effect of various factors on phenolic contents during ripening of the grape and fermentation of the wine (Bautista-Ortin, Fernandez-Fernandez, Lopez-Roca, \& Gomez-Plaza, 2007; Gil-Munoz, Gomez-Plaza, Martinez, \& Lopez-Roca, 1999; Gil-Munoz, Moreno-Perez, Vila-Lopez, Fernandez-Fernandez, Martinez-Cutillas, \& Gomez-Plaza, 2009; Gomez-Plaza, Gil-Munoz, Lopez-Roca, \& Martinez, 2000; Ivanova, Stefova, \& Vojnoski, 2009; Kelebek, Canbas, \& Selli, 2007; Koyama, Goto-Yamamoto, \& Hashizume, 2007; Mazauric \& Salmon, 2005; Monagas, Gomez-Cordoves, Bartolome, Laureano, \& Ricardo da Silva, 2003). The changes of phenolic compounds have been investigated in several studies, showing that anthocyanins are extracted from the skins and reached the maximum values in the earlier stages of fermentation, followed with extraction of tannins from the seeds with longer maceration time (Nagel \& Wulf, 1979; Price, Breen, Valladao, \& Watson, 1995).

Among the different methods, reversed phase high-performance liquid chromatography is commonly employed for the separation of complex mixtures of phenolic compounds present in wine and grape using $\mathrm{C}_{18}$ column, UV/Vis diode-array detector, and a binary solvent system with an acidified polar solvent such as aqueous solution of acetic, perchloric, phosphoric or formic 
acids (solvent $\mathrm{A}$ ) and a possibly acidified organic modifier such as methanol or acetonitrile (solvent B) (Avar et al., 2007; Castillo-Munoz, Gomez-Alonso, Garcia-Romero, \& Hermosin-Gutierrez, 2007; Gomez-Alonso, Garcia-Romero, \& Hermosin-Gutierrez, 2007; Jemal, Ouyang, \& Teitz, 1998; Palomino, Gomez-Serranillos, Slowing, Carretero, \& Villar, 2000). Phenolic compounds show characteristic absorbances in the UV/Vis region: anthocyanins have an absorbance maximum around $520 \mathrm{~nm}$, flavonols around $360 \mathrm{~nm}$ and hydroxycinnamic acids at $320 \mathrm{~nm}$. Flavan-3-ols can be detected at $280 \mathrm{~nm}$ and these substances have fluorescence properties that the other wine polyphenols do not. Liquid chromatography coupled to mass spectrometry, as a sophisticated technique, has been used for the characterisation of phenolic compounds in wine samples that allows a variety of phenolic structures to be identified (de Villiers, Vanhoenacker, Majek, \& Sandra, 2004; Garcia-Beneytez, Cabello, \& Revilla, 2003; Monagas, Suarez, Gomez-Cordoves, \& Bartolome, 2005; Perez-Magarino, Revilla, Gonzalez-SanJose, \& Beltran, 1999).

Spectrophotometry, as a more affordable technique for fast and simple routine analyses, has been used for determination of the total amounts of polyphenols (Ivanova, Stefova, \& Chinnici, 2010; Slinkard \& Singleton, 1977), flavonoids (Ivanova et al., 2010; Mazza, Fukumoto, Delaquis, Girard, \& Ewert, 1999; Zhishen, Mengcheng, \& Jianming, 1999), flavan-3-ols (Di Stefano, Cravero, \& Gentilini, 1989; Ivanova et al., 2010) and anthocyanins (Burns et al., 2000; Di Stefano et al., 1989; Ivanova et al., 2010), and for measuring the colour intensity and the hue of the wine (Glories, 1984).

In this study, HPLC-DAD coupled with ESI-IT-MS technique and spectrophotometric assays have been applied for analysis of Vranec wines obtained under different vinifications. HPLC-DAD-MS and MS-MS analyses were performed in order to identify and confirm the presence of different groups of flavonoids and nonflavonoids in the wines. Spectrophotometric methods were used for determination of total phenolic (TP), total flavonoid (TF), total anthocyanin (TA) and total flavan-3-ol $\left(\mathrm{TF}_{3-\mathrm{ol}}\right)$ contents, as well as, the colour intensity $(\mathrm{CI})$ and the hue $(\mathrm{H})$ of the wine samples in order to examine the influence of the maceration time, yeast and dose of $\mathrm{SO}_{2}$ on the extraction of polyphenols from the grape. This study provides data about the phenolic profile of this local variety grown at the Macedonian vineyards and traditionally used for making high quality wines.

\section{Materials and methods}

\subsection{Chemicals}

Methanol (HPLC-grade) was purchased from Scharlau Chemie S.A., acetic acid (puriss. p.a. grade, eluent additive for LC-MS) from Fluka. Commercially available phenolic standards (gallic, caffeic and ferulic acids, malvidin chloride, quercetin, resveratrol, resveratrol-3-glucoside and rutin) were purchased from LGC Promochem $\mathrm{GmbH}$, Szentendre, Hungary. The reagents $p$-(dimethyl-amino)cinnamaldehyde ( $p$-DMACA) and Folin-Ciocalteu were from Merck (Germany). Water was purified and deionized with a PURELAB Op-
tion-R system (ELGA Lab Water) before use. All other chemicals were of analytical grade.

\subsection{Wine samples}

Grapes from Vitis vinifera L., Vranec variety, cultivated in Skopje region (2007 vintage), were harvested at optimal maturity (22 ${ }^{\circ}$ Brix) and transported to the experimental cellar of the Department for Enology, Institute of Agriculture in Skopje, Republic of Macedonia. Vranec grapes were divided into 12 lots $(12.5 \mathrm{~kg}$ for each lot) and using mechanical crusher/destemmer, the grapes were processed separately in the same way and crushed grapes were collected in 251 plastic fermentation tanks.

Two doses of aqueous solution of potassium metabisulfite were added to the Vranec grape mashes and mixed to get six tanks having $30 \mathrm{mg} \mathrm{l}^{-1}$ (V30) and six other tanks with $70 \mathrm{mg} \mathrm{l}^{-1}$ (V70) $\mathrm{SO}_{2}$. Two yeasts (Saccharomyces cerevisiae) were used for fermentation: Vinalco (selected by the Factory for yeast and alcohol manufacture, Bitola, R. Macedonia) and Levuline CHP (isolated in the territories of Champagne and selected by CIVC 8130, Bordeaux, France), kindly supplied from Vinea winery-Štip and Tikveš-winery-Kavadarci, respectively, both from R. Macedonia. Yeasts were prepared by rehydration $(20 \mathrm{~g} / 100 \mathrm{l}$ for Vinalco and $30 \mathrm{~g} / 100 \mathrm{l}$ for Levuline) in water $\left(30^{\circ} \mathrm{C}\right)$ and applied after $15 \mathrm{~min}$. The Macedonian Vinalco yeast (Mac) was applied to three lots containing $30 \mathrm{mg} \mathrm{l}^{-1} \mathrm{SO}_{2}$ (V30-Mac), and to three other lots containing $70 \mathrm{mgl}^{-1} \mathrm{SO}_{2}$ (V70-Mac). The French yeast Levuline ( $\mathrm{Fr}$ ) was applied to the other lots either $30 \mathrm{mg} \mathrm{l}^{-1} \mathrm{SO}_{2}$ (V30-Fr) or $70 \mathrm{mg} \mathrm{l}^{-1} \mathrm{SO}_{2}$ (V70-Fr). After addition of $\mathrm{SO}_{2}$ and yeasts, maceration time of 3, 6 and 10 days was applied in order to study the effect of maceration time on phenolics extraction and their contents in the final wines. All wines were "pumped over" twice a day during the fermentation, and after the maceration period, wines were separated from the pomace by mechanically pressing. The pressed wines were stabilized at $-4{ }^{\circ} \mathrm{C}$ for a period of two weeks for tartarate stabilization and bottled. HPLC and spectrophotometric analyses were preformed after 3 months of storage of the wines in the cellar at $10-15^{\circ} \mathrm{C}$. The labels of the wine lots are presented in Table 1.

\subsection{HPLC-DAD-MS analysis}

An Agilent Series 1100 LC system combined with an Agilent 6300 Series Ion Trap (LC-MSD-TRAP-XCT_plus) MS system was used in this study. The Agilent ChemStation and Agilent LC/MSD Trap Software 5.3 were applied on the system.

The HPLC system consisted of a binary pump, a degasser, an autosampler ( $100 \mu \mathrm{l}$ sample loop), a column thermostat, and UV/ Vis diode-array detector. A Phenomenex Gemini C18 column ( $3 \mu \mathrm{m}, 50 \times 4.6 \mathrm{~mm}$ ), was used at $25^{\circ} \mathrm{C}$ for the separations. The flow rate of the mobile phase was $0.2 \mathrm{ml} \mathrm{min}^{-1}$. A multi-step gradient method was applied, using $1 \%(\mathrm{v} / \mathrm{v})$ acetic acid in water as solvent $A$ and $1 \%(v / v)$ acetic acid in methanol as solvent B. For the elution programme, the following proportions of solvent $\mathrm{B}$ were used: $0-10 \mathrm{~min}, 5-20 \%$; $10-45 \mathrm{~min}, 20-50 \%$; $45-50 \mathrm{~min}$, 50-80\%; $50-60 \mathrm{~min}, 80-90 \%$. The injection volume was $10 \mu \mathrm{l}$.

Table 1

Labels for Vranec wine samples prepared under different vinification conditions (maceration time, $\mathrm{SO}_{2}$-dose, yeast).

\begin{tabular}{|c|c|c|c|c|}
\hline \multirow[t]{2}{*}{ Vinification conditions } & \multicolumn{2}{|l|}{$30 \mathrm{mg} \mathrm{l}^{-1} \mathrm{SO}_{2}$} & \multicolumn{2}{|l|}{$70 \mathrm{mg} \mathrm{l}^{-1} \mathrm{SO}_{2}$} \\
\hline & Macedonian yeast & French yeast & Macedonian yeast & French yeast \\
\hline Three days of maceration & V30-Mac-3d & V30-Fr-3d & V70-Mac-3d & V70-Fr-3d \\
\hline Six days of maceration & V30-Mac-6d & V30-Fr-6d & V70-Mac-6d & V70-Fr-6d \\
\hline Ten days of maceration & V30-Mac-10d & V30-Fr-10d & V70-Mac-10d & V70-Fr-10d \\
\hline
\end{tabular}


The wine samples were filtered with $0.45 \mu \mathrm{m}$ filters (Iso-Disc PTFE $25-4,25 \mathrm{~mm} \times 0.45 \mu \mathrm{m}$, Supelco) and injected into the HPLCDAD-MS system.

The HPLC system was connected to the mass spectrometer equipped with electrospray ion source (ESI), operated in alternating (positive and negative) ion mode. Nitrogen was used as drying gas at $325^{\circ} \mathrm{C}$, with a flow rate of $51 \mathrm{~min}^{-1}$; the pressure of the nebulizer was set at 15 psi. The scanning mass to charge range of the ion trap mass analyzer was $50-800 \mathrm{~m} / \mathrm{z}$ with a maximum accumulation time of $200 \mathrm{~ms}$. For fragmentation, the AutoMS ${ }^{2}$ option was used. Two precursor ions were selected from each MS spectra with $4.0 \mathrm{~m} / \mathrm{z}$ isolation width. Smart Fragmentation feature of the LC/ MSD Trap was used, that ramps the fragmentation energy from $30 \%$ to $200 \%$ of the fragmentation voltage $(1 \mathrm{~V})$. A precursor ion was excluded from selection after two fragmentation spectra for $0.50 \mathrm{~min}$.

Identification of the component peaks was performed by the UV/Vis, MS and MS/MS spectra and retention times of the available standards. However, most of the compounds were identified using the ESI-IT-MS and MS-MS data compared with that found in literature (Bakker \& Timberlake, 1997; Baldi, Romani, Mulinacci, Vincieri, \& Casetta, 1995; Baranowski \& Nagel, 1981; Castillo-Munoz et al., 2007; Cheynier \& Rigaud, 1986; Chinnici et al., 2009; da Silva, Rigaud, Cheynier, Cheminat, \& Moutounet, 1991; Fulcrand, Doco, Essafi, Cheynier, \& Moutounet, 1996; Kelebek et al., 2007; Monagas et al., 2005; Remy, Fulcrand, Labarbe, Cheynier, \& Moutounet, 2000; Trousdale \& Singleton, 1983; Vitrac et al., 2001; Vivar-Quintana, Santos-Buelga, \& Rivas-Gonzalo, 2002; Wu \& Prior, 2005; Wulf \& Nagel, 1978). HPLC-MS extracted ion chromatograms (EICs) were calculated by summing up the intensities of the specified masses in the mass spectra. Ion intensities were extracted at the $\mathrm{m} / \mathrm{z}$ values of the molecular $\left(\mathrm{M}^{+}\right)$or the quasi-molecular $\left([\mathrm{M}+\mathrm{H}]^{+},[\mathrm{M}-\mathrm{H}]^{-}\right)$ions of the detected compounds. Semi-quantitative analysis was carried out using the EICs. The relative amounts of some representative components of each phenolic groups (such as caftaric and coutaric acids from the phenolic acid derivatives, myricetin-3-glucoronide and quercetin-3-glucoronide from the flavonols, (+)-catechin, (-)-epicatechin and procyanidin B2 from the flavan-3-ols and malvidin-3-glucoside, malvidin-3-acetylglucoside and malvidin-3-coumaroylglucoside from the anthocyanins) were estimated, whereas the relative peak area for these compounds was calculated from the EICs. Each peak area was compared to the peak area of gallic acid considered as internal standard, because its peak was well separated from the other peaks, without interferences and assumed that the deviations of its content were not significant. In fact, it is known that gallic acid in the wine originates from the grapes, although, some amounts could be formed as a result of hydrolysis of the gallic acid esters of flavan-3-ols, but those changes are not considered to be significant. Also, supported by the literature (Hernandez et al., 2007), the yeast strain does not influence the hydroxybenzoic acids' content, including the gallic acid, as well, thus, the amount of gallic acid could be considered as unchanged during vinification.

\subsection{Spectrophotometric measurements}

\subsubsection{General}

Analyses of polyphenols were carried out with a HP 8452 Agilent UV/Vis spectrophotometer. All measurements were performed in triplicates.

\subsubsection{Total phenolics assay}

The total phenolic contents (TP) of wines were determined using the Folin-Ciocalteu method (Ivanova et al., 2010; Slinkard \& Singleton, 1977). Briefly, an aliquot $(1 \mathrm{ml})$ of diluted wine was placed in a $10 \mathrm{ml}$ volumetric flask, containing $5 \mathrm{ml}$ of distilled water and $0.5 \mathrm{ml}$ of Folin-Ciocalteu's reagent. After $3 \mathrm{~min}, 1.5 \mathrm{ml}$ solution of $\mathrm{Na}_{2} \mathrm{CO}_{3}\left(5 \mathrm{~g} \mathrm{l}^{-1}\right)$ was added and the total volume was made up to $10 \mathrm{ml}$ with distilled water. Samples were stored for $16 \mathrm{~min}$ at $50{ }^{\circ} \mathrm{C}$ (water bath) in sealed flasks, and then cooled to room temperature. The absorbance was measured against the blank (prepared in the same way with distilled water) at $765 \mathrm{~nm}$ ( $1 \mathrm{~cm}$ optical path in the cuvette). Gallic acid was used as a standard for construction of the calibration curve. The concentration of TP was expressed in $\mathrm{mg} \mathrm{l}^{-1}$ as gallic acid equivalents.

\subsubsection{Total flavonoid assay}

Total flavonoid content (TF) was evaluated according to a colorimetric assay with aluminium chloride proposed by Zhishen et al. (1999). An aliquot of $1 \mathrm{ml}$ of appropriate diluted wine sample was placed in a $10 \mathrm{ml}$ volumetric flask, containing $4 \mathrm{ml}$ of distilled water, followed with addition of $0.3 \mathrm{ml}$ solution of $\mathrm{NaNO}_{2}$ $\left(0.5 \mathrm{gl}^{-1}\right)$. About $0.3 \mathrm{ml}$ of $\mathrm{AlCl}_{3}$ solution $\left(1 \mathrm{~g} \mathrm{l}^{-1}\right)$ was added 5 min later and after $6 \mathrm{~min}, 2 \mathrm{ml}$ of $\mathrm{NaOH}$ solution $\left(1 \mathrm{~mol}^{-1}\right)$ was added. The total volume was made up to $10 \mathrm{ml}$ with distilled water and the solution was mixed. The absorbance was measured against the blank (prepared in the same way with distilled water) at $510 \mathrm{~nm}$ ( $1 \mathrm{~cm}$ optical path in the cuvette). Catechin was used as the standard for the calibration curve and the concentration of TF was expressed in $\mathrm{mg} \mathrm{l}^{-1}$ as catechin equivalents.

\subsubsection{Total anthocyanin assay}

Determination of total anthocyanins (TA) was performed using the method described by Di Stefano et al. (1989). Samples were diluted with a solution consisting of ethanol/water $/ \mathrm{HCl}=69 / 30 / 1(\mathrm{v} /$ $\mathrm{v} / \mathrm{v}$ ) and the absorbance was measured at $540 \mathrm{~nm}(1 \mathrm{~cm}$ optical path in the cuvette). Because of the lack of malvidin-3-glucoside, the total anthocyanins content was calculated using the following equation proposed by Di Stefano et al. (1989):

$\mathrm{TA}_{540 \mathrm{~nm}}=\mathrm{A}_{540 \mathrm{~nm}} \times 16.7 \times \mathrm{d}$

$\mathrm{A}_{540 \mathrm{~nm}}$ - absorbance at $540 \mathrm{~nm}, d$ - dilution; TA content was expressed in $\mathrm{mg} \mathrm{l}^{-1}$ as malvidin-3-glucoside equivalents.

\subsubsection{Total flavan-3-ol assay}

The concentration of total flavan-3-ols $\left(\mathrm{TF}_{3-\mathrm{ol}}\right)$ was measured using the $p$-(dimethylamino)cinnamaldehyde ( $p$-DMACA) method (Di Stefano et al., 1989). Briefly, an aliquot (1 ml) of appropriate diluted sample was placed in a $10 \mathrm{ml}$ volumetric flask followed with addition of 3 drops of glycerol and $5 \mathrm{ml} \mathrm{p}$-DMACA reagent and the total volume was made up to $10 \mathrm{ml}$ with methanol. The absorbance was read at $640 \mathrm{~nm}$ after $7 \mathrm{~min}$, against the blank-methanol $(1 \mathrm{~cm}$ optical path in the cuvette). The $p$-DMACA reagent was prepared before use, containing $1 \%(\mathrm{w} / \mathrm{v}) \mathrm{p}$-DMACA in a cold mixture of methanol and $\mathrm{HCl}(4: 1)$. Catechin was used as the standard for the calibration curve and the $\mathrm{TF}_{3-\mathrm{ol}}$ was expressed as catechin equivalents ( $\mathrm{mg} \mathrm{l}^{-1} \mathrm{CE}$ ).

\subsubsection{Colour intensity and hue of wines}

The colour intensity is determined by the content and structure of the anthocyanins present in wine and defined as the sum of the absorbances at 420, 520 and $620 \mathrm{~nm}$ (Glories, 1984). The hue of the wine is defined as the ratio of $A_{420} / A_{520}$, and gives a measure of the 'hue' or redness of the wine (Glories, 1984). A direct measurement of absorbance at 420,520 and $620 \mathrm{~nm}$ was carried out using a $2 \mathrm{~mm}$ optical path.

\subsection{Statistical analysis}

Statistical treatments, including means and standard deviations were performed on results for TP, TF, $\mathrm{TF}_{3-\mathrm{ol}}, \mathrm{TA}, \mathrm{CI}$ and $\mathrm{H}$ obtained from the spectrophotometric assays. ANOVA Student-Newman- 
Keuls test was applied in order to make the multiple comparison of mean values to ascertain possible significant differences between the studied Vranec wines. Significant difference was statistically considered at the level of $p<0.05$. The statistical analyses were performed using STATISTICA 6.0 (StatSoft Inc., USA) software.

\section{Results and discussion}

\subsection{HPLC-DAD-MS analysis}

\subsubsection{General}

The HPLC-DAD-MS technique was used to describe the phenolic profile of the Vranec wines typical for Macedonia. Different families of phenolic compounds were considered in this study: phenolic acids and derivatives, stilbens, flavan-3-ols, flavonols, dihydroflavonols and pigments (Table 2).

\subsubsection{Phenolic acids and derivatives}

From the group of hydroxybenzoic acids: gallic and protocatechuic acids were detected producing the deprotonated ion $[\mathrm{M}-\mathrm{H}]^{-}$in negative ion mode at $m / z 169$ and 153 , respectively, forming fragments at $\mathrm{m} / z 125$ and 109 as a result of loss of $\mathrm{CO}_{2}$ from the carboxylate group (Monagas et al., 2005). From the hydroxycinnamic acid derivatives, caffeoyl tartaric (caftaric) and $p$-coumaroyl tartaric (coutaric) acids were detected in the wine samples with molecular masses of $m / z 311$ and 295, respectively (Baranowski \& Nagel, 1981). The $[\mathrm{M}-\mathrm{H}]^{-}$ion of caftaric acid gave two fragment ions at $m / z 179$ and 149 corresponding to the caffeic and tartaric acid moieties. The molecular ion of coutaric acid also gave two fragment ions ( $\mathrm{m} / \mathrm{z} 163$ and 149$)$ corresponding to the $p$-coumaric and tartaric acid residues.

\subsubsection{Stilbenes}

Cis/trans-resveratrol-3-glucosides were detected in the Vranec wines. The $[\mathrm{M}-\mathrm{H}]^{-}$deprotonated molecular ion of cis/trans-resveratrol-3-glucoside at $\mathrm{m} / \mathrm{z} 389$ gave a fragment ion at $\mathrm{m} / \mathrm{z} 227$ corresponding to the resveratrol moiety by loss of the glucoside group $(-162 \mathrm{Da})$.

\subsubsection{Flavonols}

The flavonol aglycone quercetin was detected in the Vranec wine as $[\mathrm{M}+\mathrm{H}]^{+}$ion at $m / z 303$. The glucoside derivatives of myricetin, quercetin, laricitrin and syringetin were identified in the wines and fragment ions $\left([\mathrm{M}+\mathrm{H}-162]^{+}\right)$corresponding to elimination of glucose molecule were detected (Castillo-Munoz et al., 2007). Myricetin-3-O-glucuronide and quercetin-3-O-glucuronide were also detected, identified by the loss of a fragment of $m / z 176$ units corresponding to glucuronic acid, as previously described (Cheynier \& Rigaud, 1986).

\subsubsection{Dihydroflavonols}

Regarding the group of dihydroflavonols, dihydroquercetin-3$O$-rhamnoside (astilbin) and dihydromyricetin-3-O-rhamnoside were detected in the wines with $[\mathrm{M}-\mathrm{H}]^{-}$molecular ions at $\mathrm{m} / \mathrm{z}$ 449 and 465, respectively, observed under negative ion mode (Trousdale \& Singleton, 1983; Vitrac et al., 2001). The fragment ions corresponded to elimination of the rhamnoside group $(-164 \mathrm{Da})$.

\subsubsection{Flavan-3-ols}

The monomeric flavan-3-ols, (+)-catechin and (-)-epicatechin with $[\mathrm{M}-\mathrm{H}]^{-}$quasi-molecular ions at $m / z 289$ and retention times at 22.4 and $29.2 \mathrm{~min}$, respectively, and (-)-epicatechin-3-O-gallate $\left(\mathrm{m} / z\right.$ 441, $\left.t_{\mathrm{R}}=34.8 \mathrm{~min}\right)$ were detected in negative ion mode. (-)-Epicatechin-3-O-gallate produced fragment ions at $m / z 289$,
Table 2

The phenolic compounds found in the Vranec wines and identified by their MS and MS-MS data in the HPLC-MS analysis.

\begin{tabular}{|c|c|c|c|}
\hline Phenolic compounds ${ }^{a}$ & $\begin{array}{l}t_{\mathrm{r}} \\
(\min )\end{array}$ & $\begin{array}{l}\text { MS } \\
(m / z)\end{array}$ & $\begin{array}{l}\text { MS-MS }{ }^{\mathrm{b}} \text { fragments } \\
(\mathrm{m} / \mathrm{z})\end{array}$ \\
\hline Phenolic acids and derivatives & & {$[\mathrm{M}-\mathrm{H}]^{-}$} & \\
\hline Gallic acid & 10.9 & 169 & 125 \\
\hline Protocatechuic acid & 16.3 & 153 & 109 \\
\hline Caftaric acid & 22.3 & 311 & 179,149 \\
\hline trans-Coutaric acid & 28.3 & 295 & 163 \\
\hline Stilbens & & {$[\mathrm{M}-\mathrm{H}]^{-}$} & \\
\hline cis-Resveratrol-3-glc & 37.6 & 389 & 227 \\
\hline trans-Resveratrol-3-glc & 46.0 & 389 & 227 \\
\hline Flavonols & & {$[\mathrm{M}+\mathrm{H}]^{+}$} & \\
\hline Myricetin-3-glc & 41.3 & 481 & 319 \\
\hline Myricetin-3-glcr & 45.6 & 495 & 319 \\
\hline Quercetin-3-glc & 46.9 & 465 & 303 \\
\hline Quercetin-3-glcr & 50.9 & 479 & 303 \\
\hline Quercetin & 55.6 & 303 & \\
\hline Laricitrin-3-glc & 47.2 & 495 & 333 \\
\hline Syringetin-3-glc & 51.6 & 509 & 347 \\
\hline Dihydroflavonols & & {$[\mathrm{M}-\mathrm{H}]^{-}$} & \\
\hline Dihydromyricetin-3-O-rha & 35.3 & 465 & 339,301 \\
\hline Astilbin & 43.3 & 449 & 303,285 \\
\hline Flavan-3-ols & & {$[\mathrm{M}-\mathrm{H}]^{-}$} & \\
\hline$(+)$-Catechin & 22.4 & 289 & $245,205,179$ \\
\hline (-)-Epicatechin & 29.2 & 289 & $245,205,179$ \\
\hline (-)-Epicatechin-3-O-gall & 34.8 & 441 & 289,169 \\
\hline Procyanidin B3 & 18.4 & 577 & $451,425,407,289$ \\
\hline Procyanidin B1 & 19.1 & 577 & $451,425,407,289$ \\
\hline Procyanidin B4 & 21.2 & 577 & $451,425,407,289$ \\
\hline Procyanidin B2 & 23.9 & 577 & $451,425,407,289$ \\
\hline Pigments & & $\mathrm{M}^{+}$ & \\
\hline Dp-3-glc & 21.4 & 465 & 303 \\
\hline Cy-3-glc & 23.7 & 449 & 287 \\
\hline Pt-3-glc & 25.2 & 479 & 317 \\
\hline Pn-3-glc & 27.6 & 463 & 301 \\
\hline Mv-3-glc & 28.4 & 493 & 331 \\
\hline Dp-3-acetylglc & 33.6 & 507 & 303 \\
\hline Cy-3-acetylglc & 36.2 & 491 & 287 \\
\hline Pt-3-acetylglc & 36.9 & 521 & 317 \\
\hline Pn-3-acetylglc & 39.7 & 505 & 301 \\
\hline Mv-3-acetylglc & 39.5 & 535 & 331 \\
\hline Dp-3-p-coumglc & 43.9 & 611 & 303 \\
\hline Cy-3-p-coumglc & 46.3 & 595 & 287 \\
\hline Pt-3-p-coumglc & 46.8 & 625 & 317 \\
\hline Pn-3-p-coumglc & 49.2 & 609 & 301 \\
\hline Mv-3-p-coumglc & 49.0 & 639 & 331 \\
\hline Pt-caffeoyl-3-glc & 42.4 & 641 & 317 \\
\hline Pn-caffeoyl-3-glc & 44.3 & 625 & 301 \\
\hline Mv-caffeoyl-3-glc & 45.6 & 655 & 331 \\
\hline Carboxypyrano-Mv-3-glc & 43.5 & 561 & 399 \\
\hline $\begin{array}{l}\text { Carboxypyrano-Mv-3- } \\
\text { acetylglc }\end{array}$ & 44.7 & 603 & 399 \\
\hline $\begin{array}{l}\text { Carboxypyrano-Mv-3-p- } \\
\text { coumglc }\end{array}$ & 51.5 & 707 & 399 \\
\hline Carboxy-pyrano- Pn-3-glc & 42.4 & 531 & 369 \\
\hline Pyrano-Mv-3-glc & 32.0 & 517 & 355 \\
\hline Pyrano-Mv-3-acetylglc & 33.6 & 559 & 355 \\
\hline Pyrano-Mv-3-p-coumglc & 41.3 & 663 & 355 \\
\hline (epi)Cat-Mv-3-glc & 18.1 & 781 & $619,601,467,373$ \\
\hline (epi)Cat-Pn-3-glc & 18.4 & 751 & $589,437,343$ \\
\hline
\end{tabular}

a glc: glucoside, glcr: glucuronide, gall: gallate, rha: rhamnoside, Dp: delphinidin, Cy: cyanidin, Pt: petunidin, Pn: peonidin, Mv: malvidin, acetylglc: acetylglucoside, p-coumglc: $p$-coumarylglucoside.

b The details on the MS-MS method are described in the Section 2.

corresponding to loss of $152 \mathrm{Da}$ as a result of the Retro Diels-Alder (RDA) fusion in the B unit and fragment ion at $m / z 169$, corresponding to the gallate residue. The flavan-3-ol dimers, detected at four different retention times at 18.4, 19.1, 21.2 and $23.9 \mathrm{~min}$ and observed four molecular ions at $\mathrm{m} / \mathrm{z} 577$ were identified as procyanidin B3, B1, B4 and B2, in agreement to the literature (da Silva et al., 1991). The quasi-molecular ion $[\mathrm{M}-\mathrm{H}]^{-}$at $m / z 557$ produced four 
fragment ions at $m / z$ 451, 425, 407 and 289 (Baldi et al., 1995; da Silva et al., 1991).

\subsubsection{Anthocyanins and pigments}

The presence of glucoside, acetylglucoside and p-coumaroylglucoside derivatives of delphinidin, cyanidin, petunidin, peonidin and malvidin was confirmed in the Vranec wines. All of them had similar fragmentation pattern containing two signals, the original $\mathrm{M}^{+}$molecular ion, and the fragments $[\mathrm{M}-162]^{+},[\mathrm{M}-204]^{+}$ and $[\mathrm{M}-308]^{+}$which are result of elimination of glucose, acetylglucose and $p$-coumaroylglucose residues, respectively (Baldi et al., 1995; Vivar-Quintana et al., 2002). In RP-HPLC, the elution order of the anthocyanidins was monoglucoside < acetylmonoglucoside $<p$-coumaroylmonoglucoside, and it was in accordance with the order of their polarity (Wulf \& Nagel, 1978). Molecular and fragment ions are listed in Table 2 and HPLC-MS EICs of anthocyanins are presented in Fig. 1.

A compound with $\mathrm{M}^{+}$molecular ion detected at $m / z 655$ and aglycone fragment at $m / z 331$, corresponding to loss of caffeoylglucoside moiety with $\mathrm{m} / \mathrm{z} 324$, was identified as malvidin-3-O-caffeoylglucoside. In addition, caffeoylglucoside derivatives of petunidin and peonidin were also detected with molecular signals at $m / z 641$ and 625 , respectively.

Pyranoanthocyanidins formed by reaction of cycloaddition of anthocyanins with pyruvic acid (Cheynier et al., 1997), called carboxy-pyrano anthocyanins, were detected in Vranec wines. Compounds with $\mathrm{M}^{+}$molecular signals at $m / z$ 561, 603 and 707 were identified as carboxy-pyrano-malvidin-3-glucoside (vitisin A), carboxy-pyrano-malvidin-3-acetyl-glucoside (acetylvitisin A) and carboxy-pyrano-malvidin-3-p-coumaroylglucoside ( $p$-coumaroylvitisin A), respectively, producing the same fragment ion at $\mathrm{m} / \mathrm{z}$

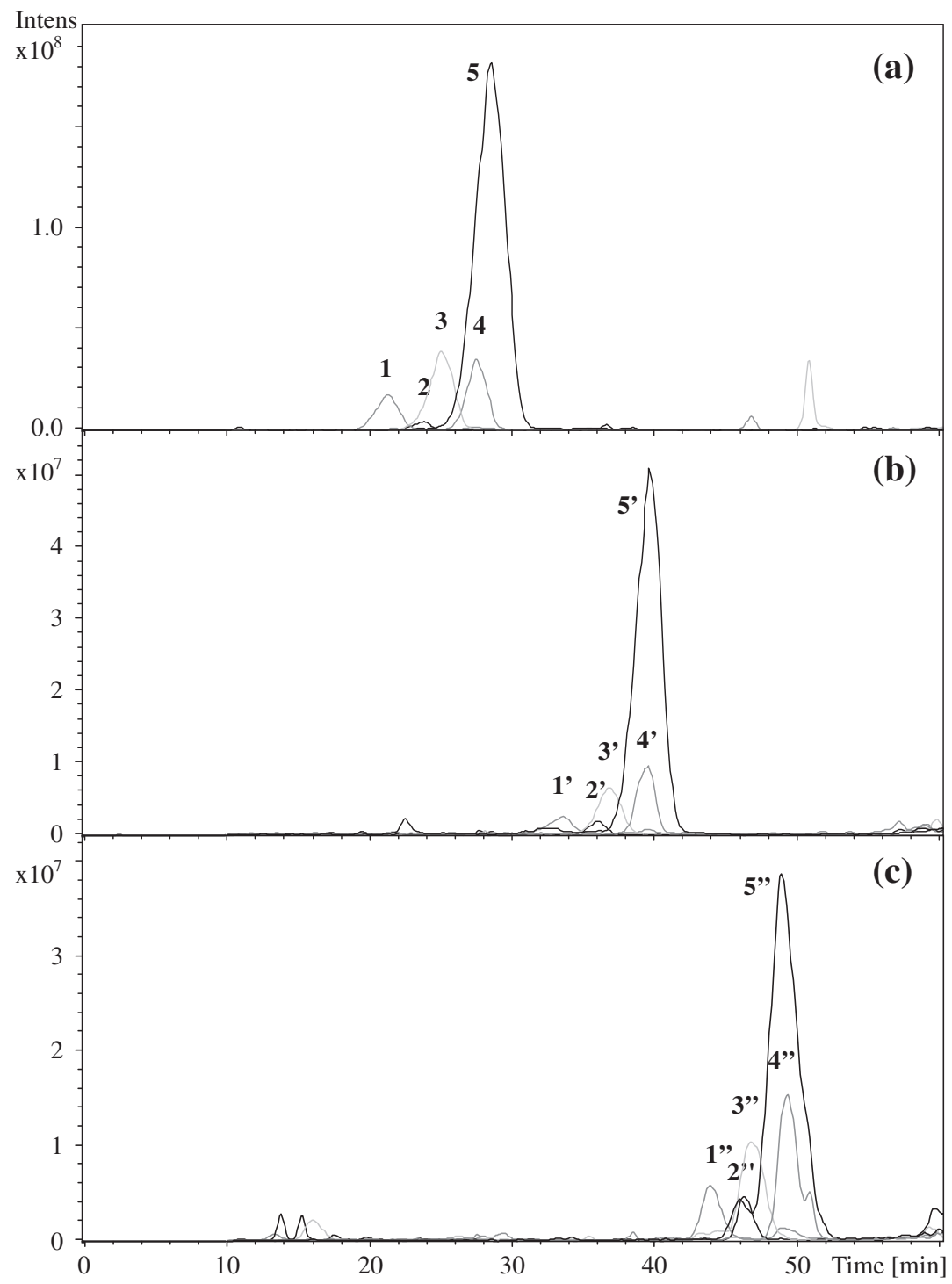

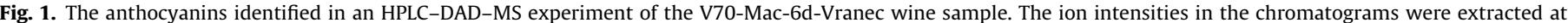

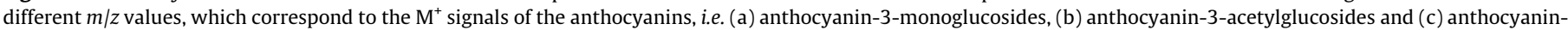

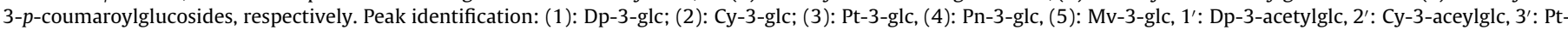

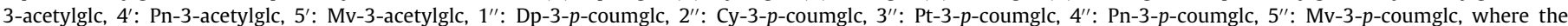

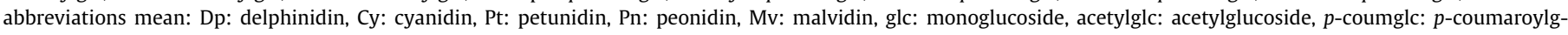

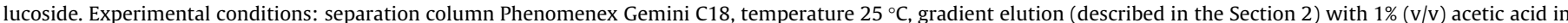

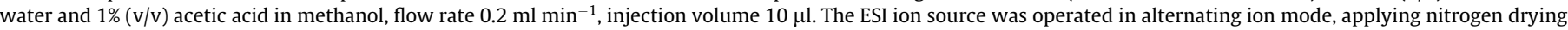
gas at $325{ }^{\circ} \mathrm{C}$ with $51 \mathrm{~min}^{-1}$ flow rate and nitrogen nebulizing gas at $15 \mathrm{psi}$. 
399 which corresponds to carboxy-pyrano-malvidin aglycone. Other pyranoanthocyanidin was identified as carboxy-pyranopeonidin-3-glucoside with $\mathrm{m} / \mathrm{z} 531$ and fragment ion at $\mathrm{m} / \mathrm{z} 369$ corresponding to elimination of glucoside group ( $-162 \mathrm{Da})$.

Compounds resulting from the reaction between anthocyanins and acetaldehyde (called pyranoanthocyanidins) (Bakker \& Timberlake, 1997; Fulcrand et al., 1996) were also found in the samples. Thus, compounds with $\mathrm{M}^{+}$molecular signals at $\mathrm{m} / \mathrm{z} 517,559$ and 663 were identified as pyrano-malvidin-3-glucoside (vitisin B), pyrano-malvidin-3-acetylglucoside (acetylvitisin B) and pyranomalvidin-3-coumaroylglucoside (coumaroylvitisin B), respectively, producing fragment ion at $\mathrm{m} / \mathrm{z} 355$ which corresponds to the elimination of glucoside ( $-162 \mathrm{Da})$, acetylglucoside ( $-204 \mathrm{Da})$ and p-coumaroylglucoside ( $-308 \mathrm{Da})$ groups.

In addition, two flavanol-anthocyanin adducts have been detected in the samples, showing a mass signals at $m / z 781$ and 751 (Remy et al., 2000). Both pigments referred to (epi)catechinmalvidin-3-glucoside and (epi)catechin-peonidin-3-glucoside, respectively. The molecular ion at $m / z 781$ produced fragment ions at $m / z 619,493,467$ and 373 and the molecular ion at $m / z 751$ produced the following fragments: $m / z 589,463,437$ and 343 . The first fragments of both compounds ( $\mathrm{m} / \mathrm{z} 619$ and 589) corresponded to elimination of glucoside residue. The fragment ion at $\mathrm{m} / \mathrm{z} 493$ is formed as a result of elimination of $126 \mathrm{Da}$ (A ring) char- acteristic for the upper units of dimers. The fragment ion at $m / z$ 467 resulted from RDA rearrangement in the flavanol molecule. Analogously, the same explanation, could be applied for the fragmentation of the molecular ion of (epi)catechin-peonidin-3-glucoside, whereas the fragment ion at $\mathrm{m} / \mathrm{z} 463$ arise from the fragmentation of the ion $m / z 589$, as a result of elimination of the A ring $\left([\mathrm{M}-126]^{+}\right)$. The fragment ion at $m / z 437$ was formed by the RDA decomposition of the flavonol.

Quantitative analysis of HPLC-DAD chromatograms (Fig. 2) was not carried out, because (i) the appropriate standards were not available and/or (ii) baseline resolution was not obtained under the separation conditions used ( $1 \mathrm{v} / \mathrm{v} \%$ acetic acid at $\mathrm{pH} 2.5-3$ ). Previous studies showed that the analysis and separation of anthocyanins by HPLC-DAD can be done at low pH (between pH 1 and 2 ), because in this way the anthocyanins will be present in their red flavylium cationic form (ca. 96\% at pH 1.5) (Wulf \& Nagel, 1978). The major drawback of the very low $\mathrm{pH}$ is, however, that it diminishes the response of the carboxylic acids in the mass spectrometer in the presence of higher concentration of acid in the mobile phase (Jemal et al., 1998). Therefore, we chose higher pH, and used $1 \mathrm{v} / \mathrm{v} \%$ acetic acid at $\mathrm{pH} 2.5-3$. With these conditions the peaks of the colourless compounds were properly separated, while, in the case of the anthocyanins, co-elution of the monoglucoside, 3-acetylglucoside and 3-p-coumaroylglucoside derivatives in the

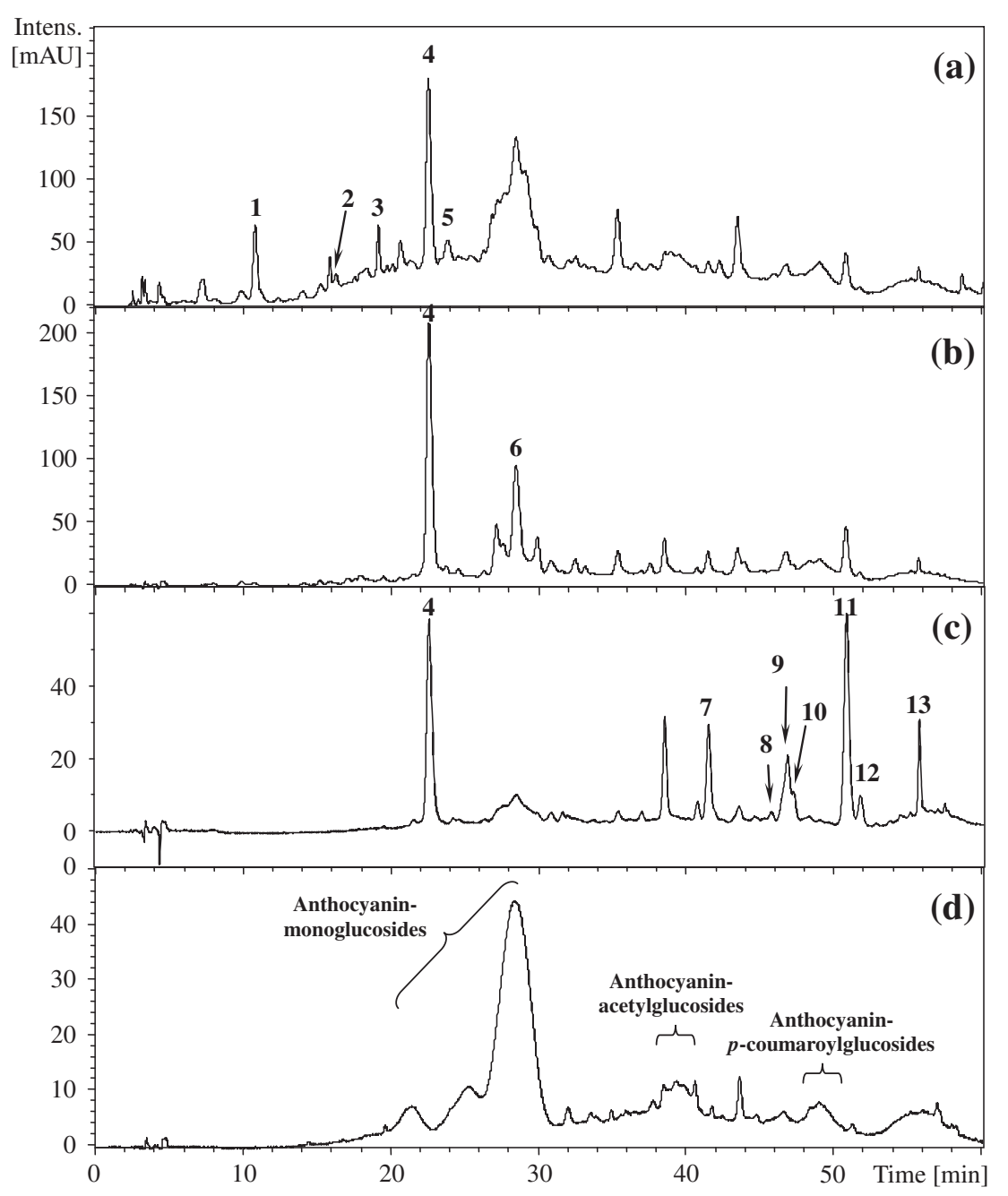

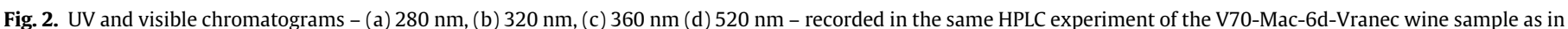

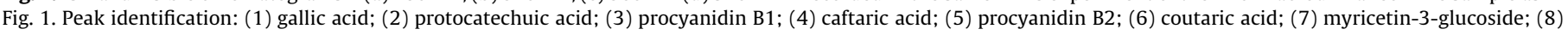
myricetin-3-glucuronide; (9) quercetin-3-glucoside; (10) laricitrin-3-glucoside; (11) quercetin-3-glucuronide; (12) syringetin-3-glucoside; (13) quercetin. 
HPLC-DAD chromatogram (detected at $520 \mathrm{~nm}$ ), were observed around 25.4, 37.1 and $47.0 \mathrm{~min}$, respectively (Fig. 2d). Therefore, in the quantitative evaluation, the relative amounts of the different components were calculated from the HPLC-MS measurements using extracted ion-chromatograms, which were characteristic to the respective components.

Investigating the effect of maceration time several observations were made. The relative amounts of some phenolic components from the groups of phenolic acid derivatives, flavonols, flavan-3ols and anthocyanins in Vranec wine (V30-Mac, macerated for 3, 6 and 10 day) were calculated from the extracted ion-peak areas (Fig. 3). The relative amounts of caftaric acid and coutaric acid were not substantially different in the wines macerated for 3,6 and 10 days, showing that these components are easily extracted from grape skins and pulp during the crushing (Fig. 3a), but slightly lower amount of caftaric acid was observed in the wines macerated for 10 days that could be due to oxidation, precipitation or hydrolysis.

The relative amounts of (+)-catechin, (-)-epicatechin and procyanidin B2 (three flavan-3-ol compounds), were highest in the wines macerated for longest time (Fig. 3b), confirming that maceration time increases the grape tannin extraction into the wine. In fact, longer maceration time increases the extraction of flavan-3-ols from the seeds, protected by a lipid layer, which is disrupted in the latest stages of vinification, when appropriate alcohol content is formed (Canals, Llaudy, Valls, Canals, \& Zamora, 2005).

The maximum level of myricetin-3-glucuronide was reached in the wines macerated for 6 days (Fig. 3a). Increasing of maceration time (10 days) led to a slight (but not significant) decrease in its content, which could be a result of precipitation, oxidative degradation or hydrolysis. The relative amount of quercetin-3-glucoronide increased by elongating the maceration time, but the difference was not significant between the wines macerated for 6 and 10 days.

The anthocyanins, together with the flavonols and skin tannins, are the first components to be extracted from the grape skins at the beginning of the fermentation. The anthocyanin content increased during the maceration and reached the highest concentration in the wines macerated for 6 days. Fig. $3 c$ shows the relative amounts of the most abundant compounds from this group: malvidin-3-glucoside, malvidin-3-acetylglucoside and malvidin-3-p-coumaroylglucoside, indicating that their maximum values were reached in the wines macerated for 6 days, but a slight decrease were obtained in wines obtained with maceration for 10 days. This indicates that the anthocyanin content depends on both, extraction, and subsequent reactions taking place in the wine. Such processes can be, for e.g., precipitation, conversion to other pigments as a result of direct reactions with flavanols, pyruvic acid and acetaldehyde, or reactions between anthocyanins and flavanols through ethyl bridges, which decrease the anthocyanin content (Bakker \& Timberlake, 1997; Fulcrand, Benabdeljalil, Rigaud, Cheynier, \& Moutounet, 1998).

The use of $\mathrm{SO}_{2}$ in winemaking is due to its ability to be an effective antioxidant, preventing the activity of the oxidases, as well as its antimicrobial property. In this research, Vranec wines were
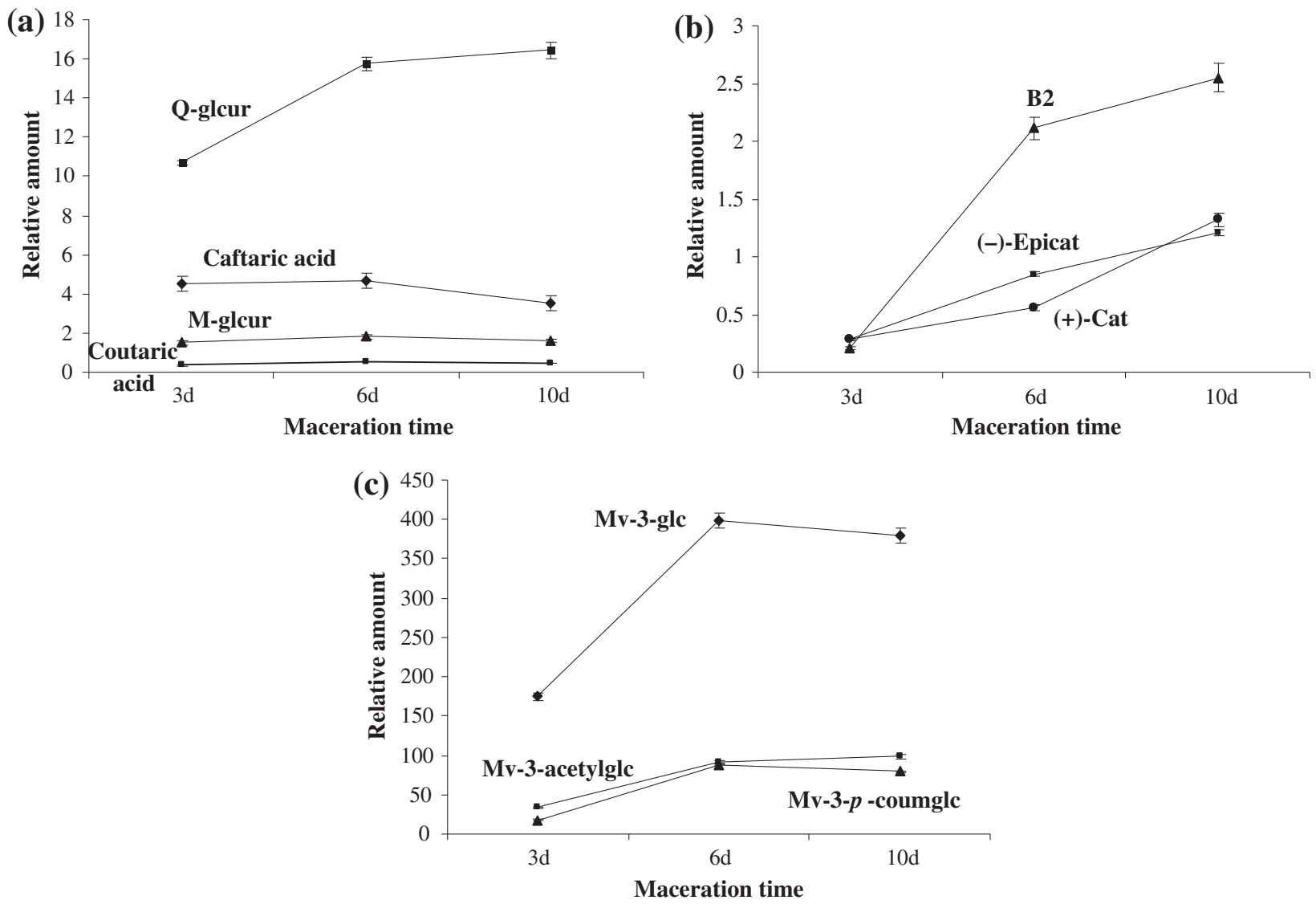

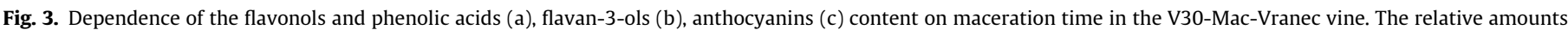

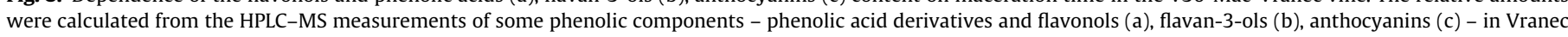

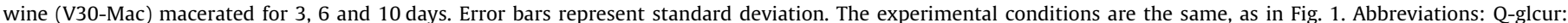

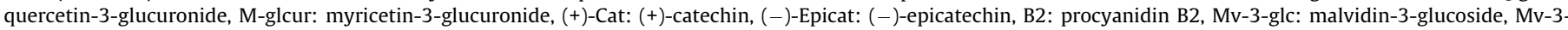

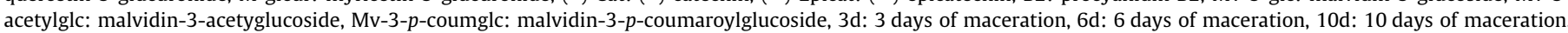


produced with two doses of $\mathrm{SO}_{2}, 30$ and $70 \mathrm{mg} \mathrm{l}^{-1}$. The extraction of polyphenols was influenced by $\mathrm{SO}_{2}$, since higher relative amounts of caftaric acid, coutaric acid, quercetin-3-glucoronide, myrecitin3-glucoronide, malvidin-3-glucoside, malvidin-3-acetylglucoside, malvidin-3-p-coumaroylglucoside, (+)-catechin, (-)-epicatechin and procyanidin B2 were found in the wines produced with higher doses of sulphur dioxide. Results obtained were in agreement with the literature confirming that $\mathrm{SO}_{2}$ increases the transfer of polyphenols into the must (Mayen, Merida, \& Medina, 1995). The use of the different yeasts (Vinalco, Macedonian yeast and Levuline, French yeast), however, did not show major influence on wine polyphenols, since the relative amounts of those compounds did not differ significantly in the wines, probably, because the yeasts have similar fermentation rates and belong to same, Saccharomyces cerevisiae species. Similar results were obtained previously for Merlot type wines, too (Ivanova et al., 2009).
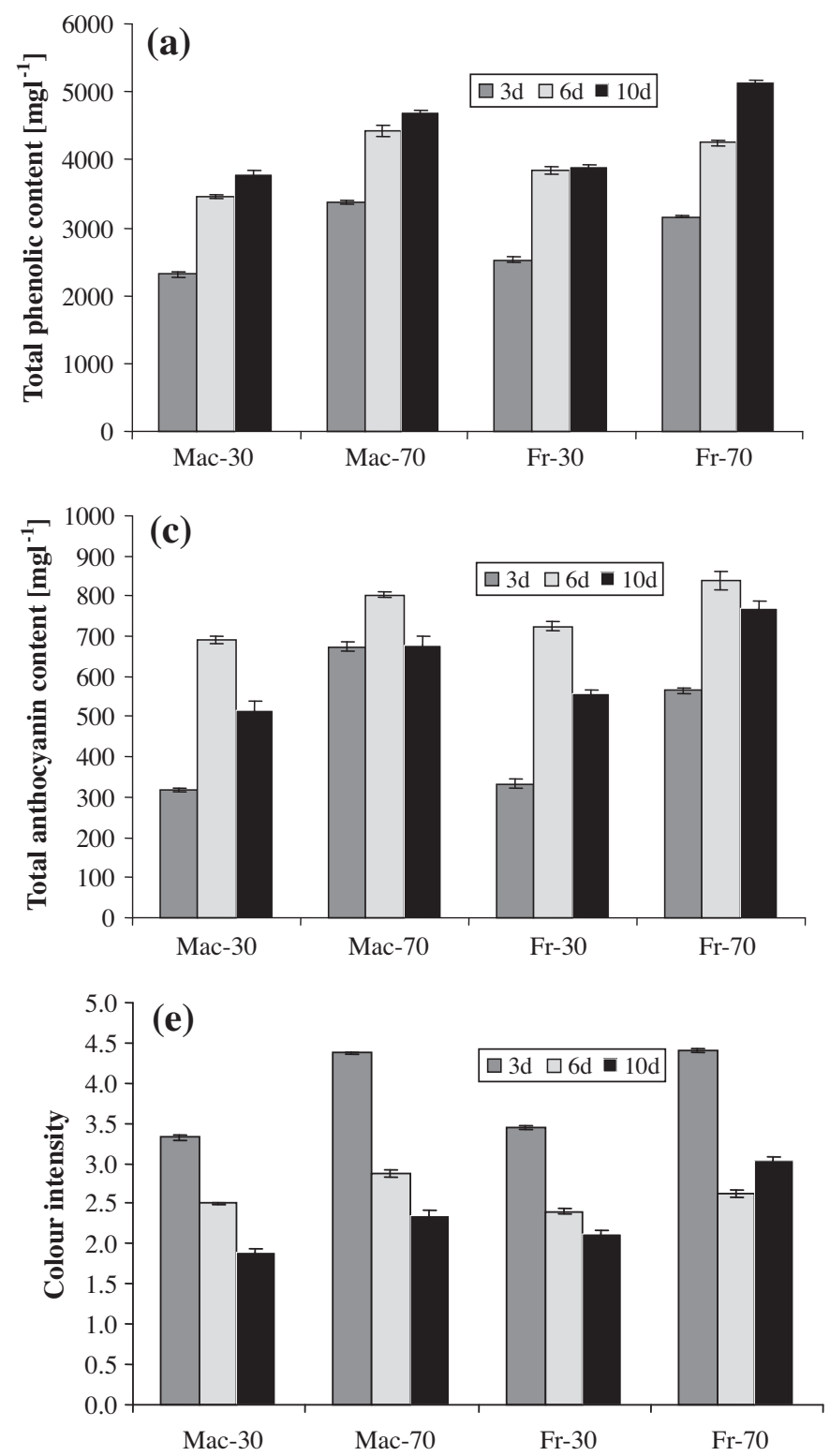

\subsection{Colorimetric methods}

\subsubsection{General}

Fast and simple spectrophotometric assays, were performed to determine the total phenolic (TP), total anthocyanin (TA), total flavonoid (TF) and total flavan-3-ol ( $\left.\mathrm{TF}_{3-\mathrm{ol}}\right)$ contents, as well as, the colour intensity $(\mathrm{CI})$ and the hue $(\mathrm{H})$ of the wines prepared under different vinification conditions (maceration time: 3, 6 and 10 day; $\mathrm{SO}_{2}$-dose: 30 and $70 \mathrm{mg} \mathrm{l}^{-1}$; yeasts: Vinalco and Levuline). The results are depicted in Fig. 4.

\subsubsection{Influence of maceration time}

Maceration time influences the concentration of polyphenols, increasing their content. Thus, wines macerated for 3 days contained the lowest amounts of $\mathrm{TP}, \mathrm{TF}$ and $\mathrm{TF}_{3-\mathrm{ol}}$, followed with increasing of their contents till the 10th day of maceration, but
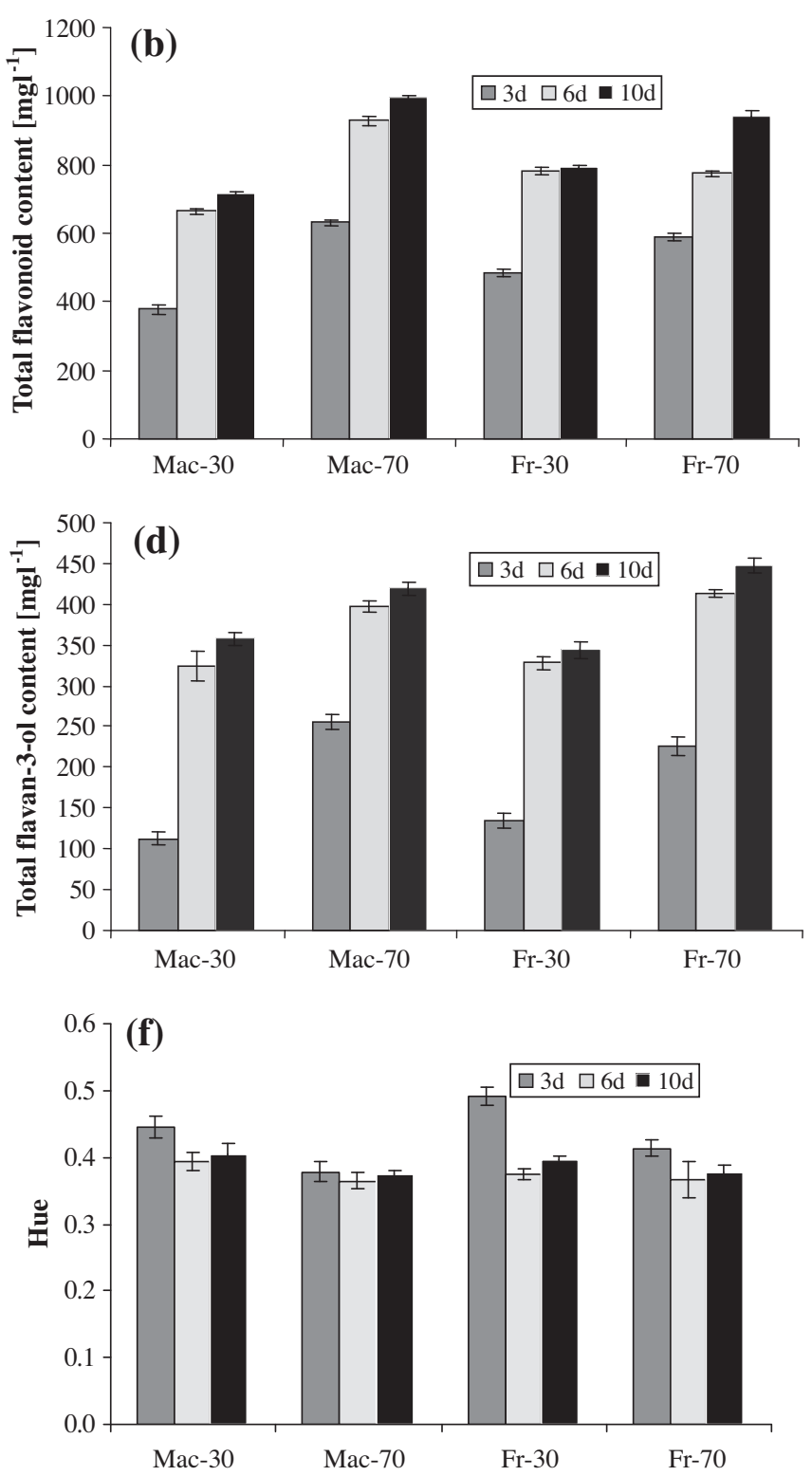

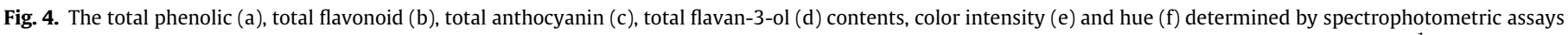

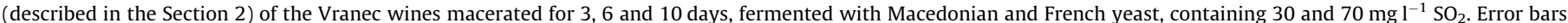

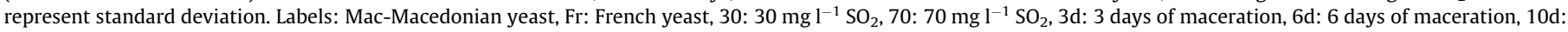
10 days of maceration. 
the difference of total phenolic contents between the 6 and 10 days macerated wines containing the same amount of $\mathrm{SO}_{2}$, was not statistically significant $(p>0.05)$. Analysis of variance revealed statistically significant differences in total phenols $(p<0.001)$ for the wines macerated for 3 and 6 days. Increased contact of the grape juice with the skins and seeds increases the extraction of polyphenols, and especially of flavan-3-ols, which are extracted in the later stages of fermentation, when the appropriate amount of alcohol will be formed which increases the tannin extraction, as generally supported by the literature (Canals et al., 2005; Gomez-Plaza, GilMunoz, Lopez-Roca, Martinez-Cutillas, \& Fernandez-Fernandez, 2001). Statistical differences between the wines obtained with different maceration time were observed for the total flavan-3-ols $(p<0.001)$ and total flavonoids $(p<0.001)$ with exception of the wines V30-Fr-6d and V30-Fr-10d, which were not statistically different regarding these components $(p>0.05)$.

The highest contents of anthocyanins was reached in the wines macerated for 6 days, followed with slight decrease with increasing of maceration time (10 days) which was not statistically significant from the wines macerated for 6 days. The results were in agreement with the literature confirming that anthocyanins reach the maximum during the early stages of vinification, decreasing till the end of fermentation (Gil-Munoz, Gomez-Plaza, Martinez, \& Lopez-Roca, 1997; Gil-Munoz et al., 1999; Nagel \& Wulf, 1979) as a result of their precipitation or conversion to other pigments, as described by Somers (1971). The colour intensity values were higher in the wines macerated for 3 days confirming that the anthocyanins are extracted mostly at the beginning of the maceration, and lower in the wines obtained with maceration of 10 days due to the conversion of anthocyanins into non pigmented species as a result of longer incubation time. The hue values of the wines were ranged from 0.34 to 0.5 indicating the dominance of red colour, which is characteristic for young wines, but no statistically significant differences $(p>0.05)$ were found between the wines regarding to the maceration time.

\subsubsection{Influence of $\mathrm{SO}_{2}$ content and yeast}

$\mathrm{SO}_{2}$ acting as an effective antioxidant and preventing the activity of the oxidases, can reduce the oxidation of phenolics allowing higher extraction of those components. In this research, two doses of $\mathrm{SO}_{2}$ were used for production of Vranec wines (30 and $70 \mathrm{mg} \mathrm{l}^{-1}$ ) in order to check its influence on extraction of phenolics during the maceration. From the results it can be concluded that $\mathrm{SO}_{2}$ has significant influence on the extraction of polyphenols $(p<0.001)$ observing higher concentrations of phenolics, anthocyanins, flavonoids and flavan-3-ols for the wines with higher content of $\mathrm{SO}_{2}$, fermented with both yeasts. Those results were in agreement with data published previously (Berg \& Akiyoshi, 1962; Ivanova et al., 2009) showing that $\mathrm{SO}_{2}$ aids the extraction of pigments.

The choice of the yeast for fermentation could have an influence on the phenolic content of the wines, absorbing the phenolic compounds on the cell walls (Mazauric \& Salmon, 2005). Comparing the results for the Vranec wines with same amount of $\mathrm{SO}_{2}$, but different yeasts, analysis of variance revealed no statistically significant differences in TP, TA, TF and $\mathrm{TF}_{3-o l}$ contents $(p>0.05)$. Probably, because the yeasts used for fermentation were from the same Saccharomyces cerevisiae species, which was in agreement with previously published data for Merlot wines (Ivanova et al., 2009).

\section{Conclusions}

The results of this study of Vranec wines confirmed that ESI-ITMS operated in negative and positive ionisation mode coupled with HPLC-DAD is a valuable tool for the identification of a wide range of phenolic compounds in wines without standard substances. The HPLC-DAD-MS and MS-MS methods allowed simultaneous analysis of phenolic acids, stilbenes, flavonols, flavan-3ols and anthocyanins without sample pretreatment, in a single HPLC run using mobile phase at $\mathrm{pH}$ 2.5-3. The results confirm the great utility of ESI-IT-MS for analysis of phenolic compounds in complex matrices, as the wines, since the coelution is not a problem so far as they have different molecular masses. The total content of phenolics, anthocyanins, flavonoids and flavan-3-ols were determined by colorimetric methods to analyse the Vranec wines vinificated under different conditions. The results showed that maceration time and $\mathrm{SO}_{2}$ amount influence significantly the extraction of phenolics, and the highest content of TP, TF and $\mathrm{TF}_{3-\mathrm{ol}}$ was observed in the wines macerated for 10 days. The concentration of anthocyanins was highest in the wines macerated for 6 days, while the content of the phenolic compounds was higher in the wines containing higher doses of $\mathrm{SO}_{2}$.

\section{Acknowledgements}

This work was supported by the CEEPUS Network (HU-0010) and by the grants GVOP-3.2.1-0168, RET 008/2005 and OTKANKTH NI-68863.

\section{References}

Avar, P., Nikfardjam, M. S. P., Kunsagi-Mate, S., Montsko, G., Szabo, Z., Boddi, K., et al (2007). Investigation of phenolic components of Hungarian wines. International Journal of Molecular Sciences, 8, 1028-1038.

Bakker, J., \& Timberlake, C. F. (1997). Isolation, identification, and characterization of new color-stable anthocyanins occurring in some red wines. Journal of Agricultural and Food Chemistry, 45, 35-43.

Baldi, A., Romani, A., Mulinacci, N., Vincieri, F. F., \& Casetta, B. (1995). HPLC/MS application to anthocyanins of Vitis vinifera L.. Journal of Agricultural and Food Chemistry, 43, 2104-2109.

Baranowski, J. D., \& Nagel, C. W. (1981). Isolation and identification of the hydroxycinnamic acid derivatives in white riesling wine. American Journal of Enology and Viticulture, 32, 5-13.

Bautista-Ortin, A. B., Fernandez-Fernandez, J. I., Lopez-Roca, J. M., \& Gomez-Plaza, E. (2007). The effects of enological practices in anthocyanins, phenolic compounds and wine colour and their dependence on grape characteristics. Journal of Food Composition and Analysis, 20, 546-552.

Berg, H. W., \& Akiyoshi, M. (1962). Color behavior during fermentation and aging of wines. American Journal of Enology and Viticulture, 13, 126-132.

Burns, J., Gardner, P. T., O’Neil, J., Crawford, S., Morecroft, I., McPhail, D. B., et al (2000). Relationship among antioxidant activity, vasodilation capacity, and phenolic content of red wines. Journal of Agricultural and Food Chemistry, 48, 220-230.

Canals, R., Llaudy, M. C., Valls, J., Canals, J. M., \& Zamora, F. (2005). Influence of ethanol concentration on the extraction of color and phenolic compounds from the skin and seeds of tempranillo grapes at different stages of ripening. Journal of Agricultural and Food Chemistry, 53, 4019-4025.

Castillo-Munoz, N., Gomez-Alonso, S., Garcia-Romero, E., \& Hermosin-Gutierrez, I. (2007). Flavonol profiles of Vitis vinifera red grapes and their single-cultivar wines. Journal of Agricultural and Food Chemistry, 55, 992-1002.

Cheynier, V., Doco, T., Fulcrand, H., Guyot, S., Le Roux, E., Souquet, J. M., et al. (1997) ESI-MS analysis of polyphenolic oligomers and polymers. Analysis, 25, M32-M37.

Cheynier, V., \& Rigaud, J. (1986). HPLC separation and characterization of flavonols in the skins of Vitis vinifera var. Cinsault. American Journal of Enology and Viticulture, 37, 248-252.

Chinnici, F., Sonni, F., Natali, N., Galassi, S., \& Riponi, C. (2009). Colour features and pigment composition of Italian carbonic macerated red wines. Food Chemistry, $113,651-657$.

da Silva, R. J. M., Rigaud, J., Cheynier, V., Cheminat, A., \& Moutounet, M. (1991). Procyanidin dimers and trimers from grape seeds. Phytochemistry, 30 1259-1264.

de Villiers, A., Vanhoenacker, G., Majek, P., \& Sandra, P. (2004). Determination of anthocyanins in wine by direct injection liquid chromatography-diode array detection-mass spectrometry and classification of wines using discriminant analysis. Journal of Chromatography A, 1054, 195-204.

Di Stefano, R., Cravero, M. C., \& Gentilini, N. (1989). Metodi per lo studio dei polifenoli dei vini. L'Enotecnico, 83-89.

Fulcrand, H., Doco, T., Essafi, N. E., Cheynier, V., \& Moutounet, M. (1996). Study of the acetaldehyde induced polymerisation of flavan-3-ols by liquid chromatography ion spray mass spectrometry. Journal of Chromatography A, 752, 85-91. 
Fulcrand, H., Benabdeljalil, C., Rigaud, J., Cheynier, V., \& Moutounet, M. (1998). A new class of wine pigments generated by reaction between pyruvic acid and grape anthocyanins. Phytochemistry, 47, 1401-1407.

Garcia-Beneytez, E., Cabello, F., \& Revilla, E. (2003). Analysis of grape and wine anthocyanins by HPLC-MS. Journal of Agricultural and Food Chemistry, 51, 5622-5629.

Gil-Munoz, R., Gomez-Plaza, E., Martinez, A., \& Lopez-Roca, J. (1999). Evolution of phenolic compounds during wine fermentation and post-fermentation: Influence of grape temperature. Journal of Food Composition and Analysis, 12, 259-272.

Gil-Munoz, R., Gomez-Plaza, E., Martinez, A., \& Lopez-Roca, J. M. (1997). Evolution of the CIELAB and other spectrophotometric parameters during wine fermentation. Influence of some pre and postfermentative factors. Food Research International, 30, 699-705.

Gil-Munoz, R., Moreno-Perez, A., Vila-Lopez, R., Fernandez-Fernandez, J. I. Martinez-Cutillas, A., \& Gomez-Plaza, E. (2009). Influence of low temperature prefermentative techniques on chromatic and phenolic characteristics of Syrah and Cabernet Sauvignon wines. European Food Research and Technology, 228, 777-788.

Glories, Y. (1984). The color of red wines. Part 2. Measurement, origin, and interpretation. Connaiss. Vigne Vin, 18, 253-271.

Gomez-Alonso, S., Garcia-Romero, E., \& Hermosin-Gutierrez, I. (2007). HPLC analysis of diverse grape and wine phenolics using direct injection and multidetection by DAD and fluorescence. Journal of Food Composition and Analysis, 20, 618-626.

Gomez-Plaza, E., Gil-Munoz, R, Lopez-Roca, J. M. \& Martinez, A (2000). Color and phenolic compounds of a young red wine. Influence of wine-making techniques, storage temperature, and length of storage time. Journal of Agricultural and Food Chemistry, 48, 736-741.

Gomez-Plaza, E., Gil-Munoz, R., Lopez-Roca, J. M., Martinez-Cutillas, A., \& Fernandez-Fernandez, J. I. (2001). Phenolic compounds and color stability of red wines: Effect of skin maceration time. American Journal of Enology and Viticulture, 52, 266-270.

Guerrero, R. F., Liazid, A., Palma, M., Puertas, B., Gonzalez-Barrio, R., Gil-Izquierdo, A., et al. (2009). Phenolic characterisation of red grapes autochthonous to Andalusia. Food Chemistry, 112, 949-955.

Hernandez, T., Estrella, I., Perez-Gordo, M., Alegria, E. G., Tenorio, C., Ruiz-Larrrea, F. et al. (2007). Contribution of malolactic fermentation by Oenococcus oeni and Lactobacillus plantarum to the changes in the nonanthocyanin polyphenolic composition of red wine. Journal of Agricultural and Food Chemistry, 55, 5260-5266.

Ivanova, V., Stefova, M., \& Chinnici, F. (2010). Determination of the polyphenol contents in Macedonian grapes and wines by standardized spectrophotometric methods. Journal of the Serbian Chemical Society, 75, 45-59.

Ivanova, V., Stefova, M., \& Vojnoski, B. (2009). Assay of phenolic profile of Merlot wines from Macedonia: Effect of maceration time, storage, $\mathrm{SO}_{2}$ and temperature of storage. Macedonian Journal of Chemistry and Chemical Engineering, 28, 141-149.

Jemal, M., Ouyang, Z., \& Teitz, D. S. (1998). High performance liquid chromatography mobile phase composition optimization for the quantitative determination of a carboxylic acid compound in human plasma by negative ion electrospray high performance liquid chromatography tandem mass spectrometry. Rapid Communications in Mass Spectrometry, 12, 429-434.

Kelebek, H., Canbas, A., \& Selli, S. (2007). HPLC-DAD-MS analysis of anthocyanins in rose wine made from cv. Öküzgözü grapes, and effect of maceration time on anthocyanin content. Chromatographia, 66, 207-212.

Koyama, K., Goto-Yamamoto, N., \& Hashizume, K. (2007). Influence of maceration temperature in red wine vinification on extraction of phenolics from berry skins and seeds of grape (Vitis vinifera). Bioscience, Biotechnology, and Biochemistry, 71, 958-965.
Mayen, M., Merida, J., \& Medina, M. (1995). Flavonoid and nonflavonoid compounds during fermentation and postfermentation standing of musts from CabernetSauvignon and Tempranillo grapes. American Journal of Enology and Viticulture, 46, 255-261.

Mazauric, J. P., \& Salmon, J. M. (2005). Interactions between yeast lees and wine polyphenols during simulation of wine aging: I. Analysis of remnant polyphenolic compounds in the resulting wines. Journal of Agricultural and Food Chemistry, 53, 5647-5653.

Mazza, G., Fukumoto, L., Delaquis, P., Girard, B., \& Ewert, B. (1999). Anthocyanins, phenolics, and color of Cabernet Franc, Merlot, and Pinot Noir wines from British Columbia. Journal of Agricultural and Food Chemistry, 47, 4009-4017.

Monagas, M., Gomez-Cordoves, C., Bartolome, B., Laureano, O., \& Ricardo da Silva, J. M. (2003). Monomeric, oligomeric, and polymeric flavan-3-ol composition of wines and grapes from Vitis vinifera L. cv. Graciano, Tempranillo, and Cabernet Sauvignon. Journal of Agricultural and Food Chemistry, 51, 6475-6481.

Monagas, M., Suarez, R., Gomez-Cordoves, C., \& Bartolome, B. (2005). Simultaneous determination of nonanthocyanin phenolic compounds in red wines by HPLCDAD/ESI-MS. American Journal of Enology and Viticulture, 56, 139-147.

Nagel, C. W., \& Wulf, L. W. (1979). Changes in the anthocyanins, flavonoids and hydroxycinnamic acid esters during fermentation and aging of Merlot and Cabernet Sauvignon. American Journal of Enology and Viticulture, 30, 111-116.

Palomino, O., Gomez-Serranillos, M. P., Slowing, K., Carretero, E., \& Villar, A. (2000). Study of polyphenols in grape berries by reversed-phase high-performance liquid chromatography. Journal of Chromatography A, 870, 449-451.

Perez-Magarino, S., Revilla, I., Gonzalez-SanJose, M. L., \& Beltran, S. (1999). Various applications of liquid chromatography-mass spectrometry to the analysis of phenolic compounds. Journal of Chromatography A, 847, 75-81.

Price, S. F., Breen, P. J., Valladao, M., \& Watson, B. T. (1995). Cluster sun exposure and quercetin in Pinot noir grapes and wine. American Journal of Enology and Viticulture, 46, 187-194.

Remy, S., Fulcrand, H., Labarbe, B., Cheynier, V., \& Moutounet, M. (2000). First confirmation in red wine of products resulting from direct anthocyanin-tannin reactions. Journal of the Science of Food and Agriculture, 80, 745-751.

Sarni-Manchado, P., Cheynier, V., \& Moutounet, M. (1999). Interactions of grape seed tannins with salivary proteins. Journal of Agricultural and Food Chemistry, $47,42-47$.

Slinkard, K., \& Singleton, V. L. (1977). Total phenol analysis: Automation and comparison with manual methods. American Journal of Enology and Viticulture, $28,49-55$

Somers, T. C. (1971). The polymeric nature of wine pigments. Phytochemistry, 10 2175-2186

Trousdale, E. K., \& Singleton, V. L. (1983). Astilbin and engeletin in grapes and wine. Phytochemistry, 22, 619-620.

Vitrac, X., Castagnino, C., Waffo-Teguo, P., Delaunay, J. C., Vercauteren, J., Monti, J. P., et al. (2001). Polyphenols newly extracted in red wine from southwestern France by centrifugal partition chromatography. Journal of Agricultural and Food Chemistry, 49, 5934-5938.

Vivar-Quintana, A. M., Santos-Buelga, C., \& Rivas-Gonzalo, J. C. (2002). Anthocyaninderived pigments and colour of red wines. Analytica Chimica Acta, 458, 147-155.

Wu, X., \& Prior, R. L. (2005). Identification and characterization of anthocyanins by high-performance liquid chromatography-electrospray ionization-tandem mass spectrometry in common foods in the United States: Vegetables, nuts, and grains. Journal of Agricultural and Food Chemistry, 53, 3101-3113.

Wulf, L. W., \& Nagel, C. W. (1978). High-pressure liquid-chromatographic separation of anthocyanins of Vitis vinifera. American Journal of Enology and Viticulture, 29, 42-49.

Zhishen, J., Mengcheng, T., \& Jianming, W. (1999). The determination of flavonoid contents in mulberry and their scavenging effects on superoxide radicals. Food Chemistry, 64, 555-559. 